\title{
Gender Communication: A Comparative Analysis of Communicational Approaches of Men and Women at Workplaces
}

\author{
${ }^{1}$ Prof Vinita Mohindra, ${ }^{2}$ Dr. Samina Azhar \\ $\left({ }^{1}\right.$ Head, Department of Humanities\& Social Sciences, Maulana Azad National Institute of Technology, Bhopal \\ India) \\ $\left({ }^{2}\right.$ Assistant Professor Department of Humanities\& Social Sciences, Maulana Azad National Institute of \\ Technology, Bhopal India)
}

\begin{abstract}
Globalization has resulted in multi-cultural and diverse workforces across the globe. Diversity in a workplace increases adaptability amongst employees; different talents of various individuals have become great resources, which also result in a pool of unique contributions. As a diverse genders and culture comes together, it provides a spectrum of viewpoints to meet objectives and accomplish goals. Thus diverse work force is an environment where people accept differences rather than deny them. If we pay attention to gender differences, we just might untangle the gender communications knots and get the job done faster and make working environment hassle free. Successful organizations need to create effective communication within a diverse workforce. In order to do so, it is necessary tofocus on the gender differences in communication patterns. Overlooking the differences between the two gender roles can cause confusion and biases thus consequently having a negative impact on the overall organizational performance. However, gender issues arising from misunderstanding could be reduced within the organization by establishing equilibrium between men and women. The only way to have a healthy working atmosphere within an organization is to identify the differences and find ways to bridge the communication gulf between the sexes. Through two quizzes an attempt has been made in this work to explore different approaches followed by male and female associates to communicate in an organization.
\end{abstract}

\section{Introduction-}

Since last two to three decades there has been a growing discussion on gender based communication at workplace with more women entering managerial ranks a rapid increase in number of women in the workplace worldwide has presented a challenging situation for the communication cycle within the organization. Hence the communication between colleagues of opposite sexes becomes more significant for the success of the organization. Books such as Deborah Tannen's (1990) You Just Don't Understand: Men and Women in Conversation and (1994) Talking from 9 to 5, Marian Woodall's (1990) How to Talk so Men Will Listen, and John Gray's (1992) Women are from Venus, Men are from Mars have immensely contributed to the recognition of gender communication.

Gender communication differences begin during childhood. Girls are told to use their manners, play quietly, and be ladylike. However it is okay for boys to use rough language, play loudly, and be rambunctious. Girls are allowed to show feelings. For example, if a small girl scrapes her knee and starts to cry, she is nurtured. If a boy has the same minor injury, he is told not to cry and be tough. Hence girls develop a relational style of interaction whereas boys develop a competitive style of interaction. While studying the contrasts between men and women in the workplace, one should not remember neither one gender's style is better than the other. Men are perfectly right to be more direct while women are perfectly right to be people-oriented, even in the workplace. "Women are nurturers, and this quality can enhance any work situation. Men are natural providers. They are task-oriented and like to get the job done. These two styles complement each other perfectly, as long as there is an openness and understanding on each part".l

Talking to Nancy Clark Martha Barletta says, "When men communicate they're concerned with conveying information and establishing status. When women communicate they're concerned with conveying information and building connections...... When men are not successful, they tend to attribute it to external factors. The opposite is true for women. When women have a failure, they tend to attribute it to their own shortcomings. And when they succeed, they tend to link it to external factors, such as teamwork and luck.... Since men's gender culture is hierarchical, their main concern is ensuring that they get up the corporate ladder. So they express, and are expected to express, their accomplishments and their strengths. Women are in an egalitarian gender culture so they tend to downplay their own role in the success. Women see any attempt to put oneself up as disruptive to building connections". ${ }^{2}$

Research indicates men and women socialize differently and consequently, have diverse styles of speaking. "The sexes often speak virtually different languages. Tannen calls it "report talk" versus. "rapport 
talk.". 3

\section{Rapport talk is indirect style containing the following features}

- Use of Qualifiers, Succinct style

- Apologizing

- Taking Blame

- Thanks

- Maintaining an Appearance of Equality, Downplaying Qualifications

- Considering the other Person and relationship

- Downplaying Authority

\section{Report talk includes the following features}

- Direct Requests

- Longer Talk at Meetings

- Ritual Fighting, Teasing, Banter

- Giving Advice to Solve Problems rather than Showing Support

- Mixing Business and Non-business talk

- Rarely Give Praise or Compliments

- Avoiding the One-down Position, Downplaying Doubts

According to Deborah Tannen, "men are more likely to engage in what is referred to, as report talk, which is primarily characterized by "focus on content". Men talk about affairs that are public matters, such as sports or politics. During report talk, men demonstrate their knowledge about a subject and will give general information about the topic". She further says "that rapport talk, on the other hand, is designed to establish relationships and make people in relationships feel closer to each other. Women are engaged in this kind of talk more often than men. Rapport talk deals with more intimate matters than report talk hence includes topics such as family and marital relationships". 5

The male communication pattern and traits tend to be honest, direct, and factual. It is considered "report" type talk. The communication behaviors men tend to possess are as follows:

- reason

- $\quad \operatorname{logic}$

- power

- rank

- $\quad$ status

- compete

- winning

- team

- think

Men view conversation as a means to exchange information and problem solve. Men stay away from personal topics and discuss events, sports, news, and facts. They tell more stories and jokes than women as a way to show status and power. Men are direct, blunt, and speech includes slang or swears words. Men get straight to work on a task and build relationships while working on the project. Men reflect and process information for decision making internally.

Women avoid using aggressive and threatening language irrespective of their position. They exhibit their subordinate status by being polite and soft spoken and demonstrate their authority in the same way but with a little bit of discipline and straight face. In both the cases they avoid direct and threatening communication. Women want to be with their families, help others, feel respected and cared about, be a part of a community, be proud of the company they work for and be trusted. All of this reflects their need for connection and relationship, which is also the main reason why women are so well-suited for business their natural ability to develop and maintain relationships. Women talk to build rapport and make connections. They discuss personal topics like relationships, feelings, and past experiences. Women take turns communicating. Women tend to be indirect, tactful, and use more courtesy words. Women accomplish tasks by building relationships first. Women talk out loud to others, processing information externally for decision making.

The female communication pattern and traits tend to be nurturing, indirect, and respectful. It is considered "rapport" type talk. The communication behaviors women tend to possess are as follows:

- feeling

- empathy

- harmony

- closeness

- relationships

- sharing 
Gender Communication: A Comparative Analysis of Communicational Approaches of Men and

- cooperation

- group

- $\quad$ intuitive

Considering nonverbal communication women gain an upper hand over their male counterparts Women interpret nonverbal communication better than men. Men are less comfortable with making eye contact than women. Apparently, it has something to do with dominance, power and status. Direct eye contact is a sign of emotion. So, the less eye contact shared the less emotion. In terms of gestures, postures and facial expressions, results appear to be mixed. But, basically, men and women use gestures, postures, touch and facial expressions differently. For example, women tend to smile and use facial expressions more than men do. Men appear more relaxed in posture while women appear tenser.

Men and women communicate on different levels and their communicational approaches are also different. It can be ascertained from the following presentation:

Levels of Communication between Men and Women

\begin{tabular}{|c|c|c|}
\hline S.No & Men & Women \\
\hline 1 & $\begin{array}{l}\text { Men keep their problems to themselves } \\
\text { and don't see the point in sharing } \\
\text { personal issues. }\end{array}$ & $\begin{array}{l}\text { Women are more likely to talk to other women when } \\
\text { they have a problem or need to make a decision. }\end{array}$ \\
\hline 2 & $\begin{array}{l}\text { Men tend to relate to other men on one- } \\
\text { up and one-down basis. Status and } \\
\text { dominance is important. }\end{array}$ & $\begin{array}{l}\text { They are more relationship oriented, and look for } \\
\text { commonalities and ways to connect with other } \\
\text { women. }\end{array}$ \\
\hline 3 & $\begin{array}{l}\text { Men focus on talking and providing } \\
\text { information rather than asking } \\
\text { questions. They share experiences as a } \\
\text { way of being one-up. }\end{array}$ & $\begin{array}{l}\text { They focus on building rapport, by sharing } \\
\text { experiences and asking questions. }\end{array}$ \\
\hline 4 & $\begin{array}{l}\text { Men can have a disagreement, move on } \\
\text { to another subject and go get a drink } \\
\text { together }\end{array}$ & $\begin{array}{l}\text { If women have a disagreement with each other it } \\
\text { affects all aspects of their relationship. }\end{array}$ \\
\hline 5 & $\begin{array}{l}\text { Men build relationships while they are } \\
\text { working on tasks with each other. }\end{array}$ & Get things done at work by building relationships. \\
\hline 6 & $\begin{array}{l}\text { Men move to solutions and problem } \\
\text { solving right away. }\end{array}$ & $\begin{array}{l}\text { Women want to talk about the problems and solve } \\
\text { them collaboratively. }\end{array}$ \\
\hline 7 & $\begin{array}{l}\text { For men asking for help reflects an } \\
\text { inability to achieve on one's own merit. }\end{array}$ & Offering help and advice is a sign of care. \\
\hline 8 & $\begin{array}{l}\text { Men listen to the main points. They are } \\
\text { selective listeners. }\end{array}$ & $\begin{array}{l}\text { They listen to each and every word; they show } \\
\text { attentiveness through verbal and non-verbal cues. }\end{array}$ \\
\hline
\end{tabular}

\section{Table1: Levels of Communication between Men and Women}

Earlier women used to be much more "quiet and passive" in the workplace due to the relatively small number of female employees in comparison to males. Women today, on the other hand, have begun assuming their positions by using all their God given powers of intelligence and organization. Warren Farrell, author of Why Men Are the Way They Are, explains that men are jealous of the "beauty power"6 that allows women to get certain things based on their physical assets. It is totally absurd conclusion to be honest perhaps it's less that women use their beauty, and more likely that men judge them based on their physical beauty.

According to some researchers, men use an instrumental style of communication. Instrumental style of communication for men is to focus on identifying goals and finding a solution. Women communicate in an expressive style. The expressive style involves emotions and having a perspective of being sensitive to how others feel. A deeper awareness of how differently men and women communicate is necessary in order to prevent these gender differences from leading to resentment, decreased productivity and workplace stress.

Whether they like it or not, men have to accept, once and for all, that women are marching up the corporate ladder confidently and with full speed ahead. The study of differences cannot be based on stereotypes suppose that the question is: who interrupts more, men or women? Some studies will have found that men interrupt more, others that women do, and others may have found no significant difference. In some studies the reported gender difference will be large, while in others it will be much smaller. Therefore number of men and women whose communication styles were to be investigated will vary from study to study.

As the aim of the study is to examine the various approaches adopted by different genders, two quizzes involving people of opposite genders at workplace were distributed to the members of different organizations. 
Gender Communication: A Comparative Analysis of Communicational Approaches of Men and Their responses were analysed to find out communicational strategies, styles and approaches adopted by a male or a female. The analysis helped in reaching the conclusion so that the objectives of the study can be attained.

\section{Gender Communication Quiz I}

The participants were asked to indicate beside each adjective below which gender the word best describes. They were instructed to tick in the relevant column or in the both columns if the word immediately brings to mind both men and women. The following is the outcome:

\begin{tabular}{|c|c|c|}
\hline Words & Male & Female \\
\hline Logical & 12 & 3 \\
\hline Intuitive & 9 & 6 \\
\hline Gentle & 6 & 9 \\
\hline Fashionable & 5 & 10 \\
\hline Talkative & 7 & 8 \\
\hline Critical & 4 & 11 \\
\hline Outspoken & 5 & 10 \\
\hline Aggressive & 5 & 10 \\
\hline Funny & 8 & 7 \\
\hline Emotional & 5 & 10 \\
\hline Assertive & 7 & 8 \\
\hline Manipulative & 7 & 8 \\
\hline Interrupt More & 9 & 6 \\
\hline
\end{tabular}

\section{Graphical Representations}

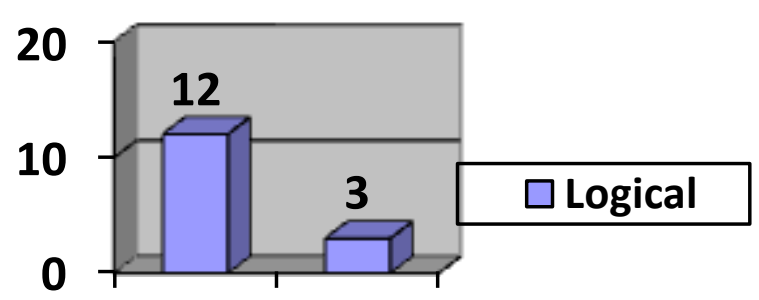

Male Female

Figure1.2

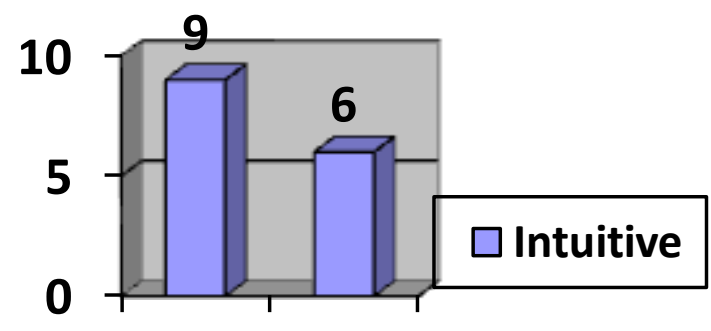

Male Female

Figure: 1.3

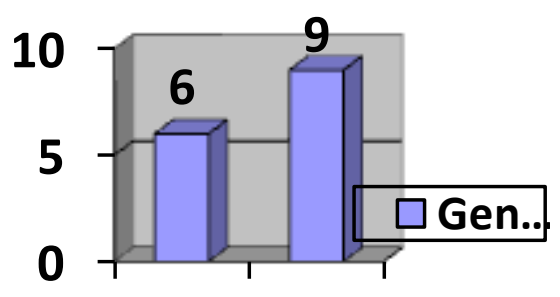

MaleFemale

Figure: 1.4 


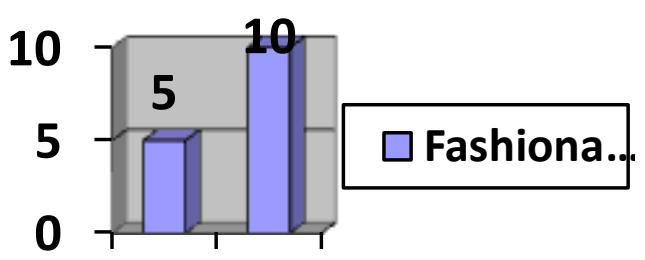

Matremale

Figure: 1.5

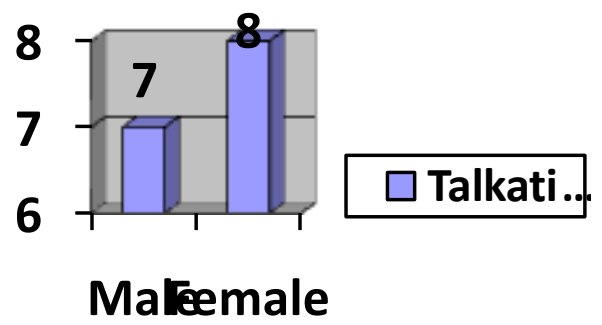

Figure: 1.6
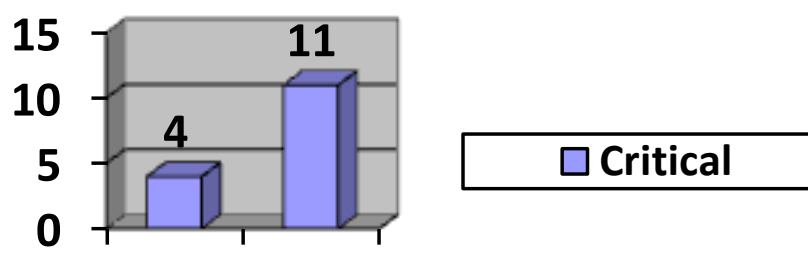

\section{Male Female}

Figure: 1.7

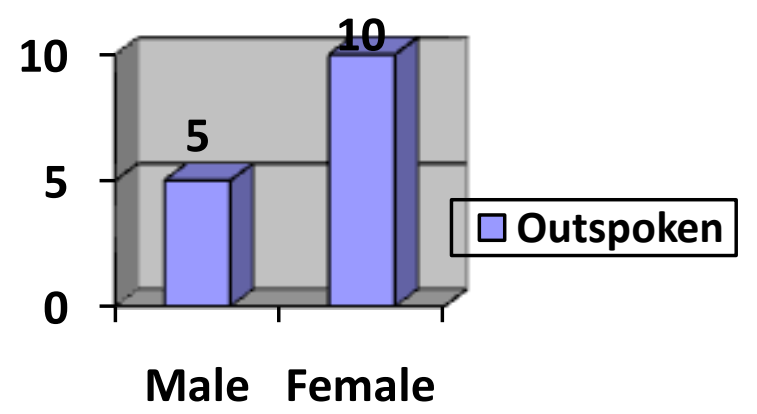

Figure: 1.8

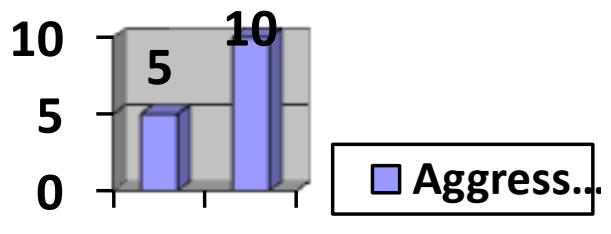

Mafremale

Figure: 1.9 


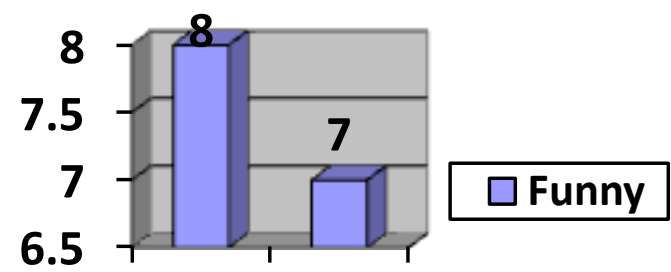

\section{Male Female}

Figure: 2.1
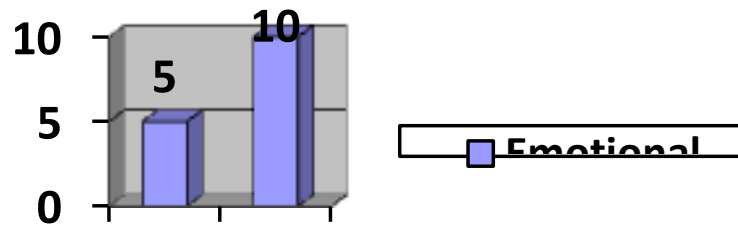

\section{Malfemale}

Figure: 2.2

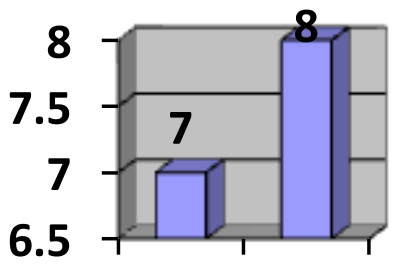

$\square$ Assertive

\section{MaleFemale}

Figure: 2.3

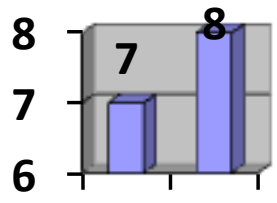

Dnanniniolativa

\section{MaFemale}

Figure: 2.4

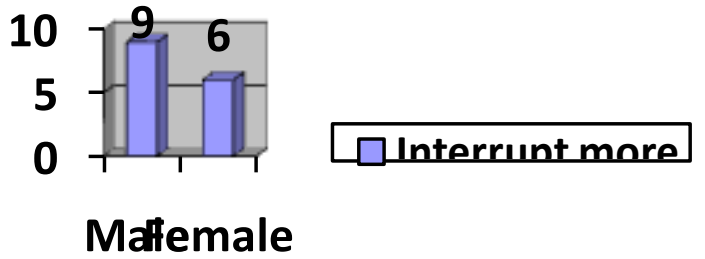

Figure: 2.5

It clearly reflects the findings amongst a group of individuals as to how they feel about the adjective, whether it describes a male or a female. For most cases the results are very close calls yet are very decisive for the others. The graphs have different scales and are to be interrupted with the values, from which we can draft the following conclusions. Fashionable is a term which earlier used to be synonyms to a lady but now we have seen a shift as even other gender is finding reasons to look good. Talkative was a trait associated with women but now we see that even males are finding space and points to be more talkative. Still women are found to more emotional yet intuitive and being diplomatic is something that is in them since ages. Males are still more rational and can interpret data more easily and are yet more hilarious. Taking into account the trait of being critical women have always had an edge and are still making the others bow down to their trait though still men are 
more logical. Therefore we have to consider that these differences are typical. Not all traits listed under male or female are strictly one or the other. Anyone can have any combination of traits.

The key point demonstrated by the exercise is this: just because a woman may be emotional, too sensitive in certain situations, talkative, and caring, does not preclude her from also being decisive, competent, intelligent, and driven. And just because a man might be decisive, aggressive, logical, and independent does not mean that he is not also sensitive, and gentle in certain situations, and a good cook. This confirms that the longstanding expectation that women will serve and care for others is not unrelated to their position as the second sex.

\section{Gender Communication Quiz}

Men and women in business can be equal in almost every way: position, experience, expertise, professional experience, educational background, and intelligence. Despite these similarities, chances are men and women can be very different in one critical area: the way in which they communicate. It's not that an inherently male or female way of communication is better or more correct; the styles are just different. Understanding the inherent communication differences between men and women will help you to enhance your ability to communicate successfully with others, and to hear, interpret and comprehend others' messages without judgment.

In the second quiz a questionnaire of fifteen questions was distributed to fifty professionals of diverse gender and fields including medical, technical and academics. It has been found while cataloguing the answers that the statements related to personal affection, bundle of gestures and talking with intuition, all traits, are associated to polite gender. Here by polite gender we refer to the females. Females are often intuitive and even at times appear oracular. As far as the personal space is considered men are found to be the most probable invaders of all times. Getting to some talking business, one wouldn't find any discrepancies in this summary one would without any argument agree to the findings that females tend to speak less while they are in a conversation with males and the findings also indicate that they speak at turtle rates.

The quiz depicts various traditional norms related to the standard patterns of communication between opposite genders. It tries to explore with what women wish men knew about them or what men wish women knew about them. The green colour in the pie chart represents false whereas red colour represents true.

\section{Graphical Orientations}

1. Men talk more than women

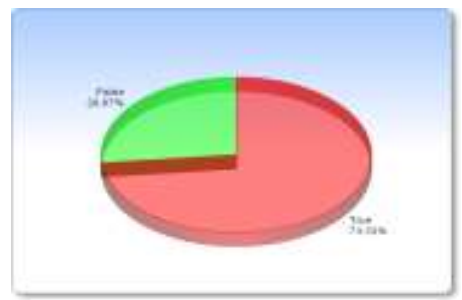

Figure:2.6

2. Men are more likely to interrupt women than they are to interrupt other men

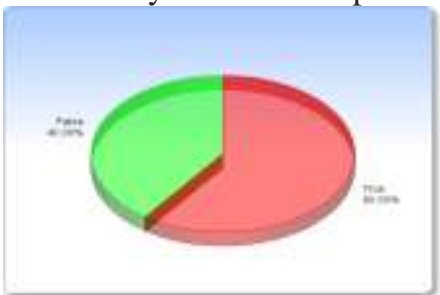

Figure:2.7

3. Nonverbal messages carry more weight than verbal messages.

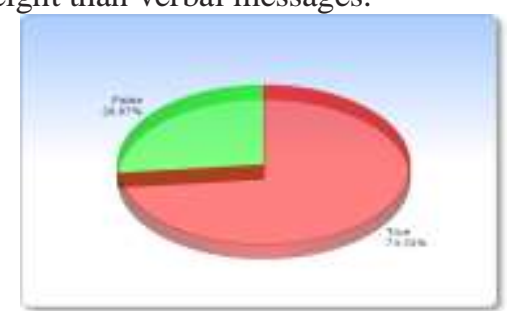

Figure:2.8 
Gender Communication: A Comparative Analysis of Communicational Approaches of Men and

4. Female managers communicate with more emotional openness and drama than male managers

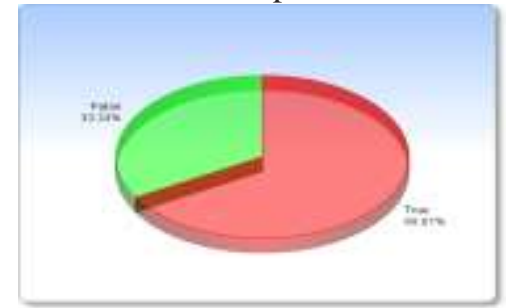

Figure:2.9

5. Men not only control the content of conversations, they also work harder in keeping conversations going

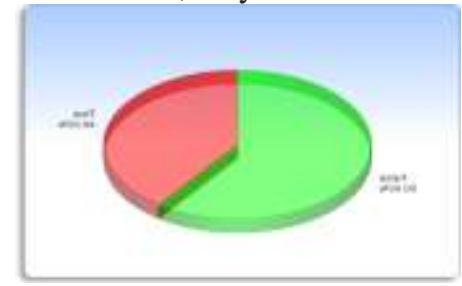

Figure: 3.1

6. When people hear general words such as "mankind" and "he," they respond inclusively, indicating: that the terms apply to both sexes.

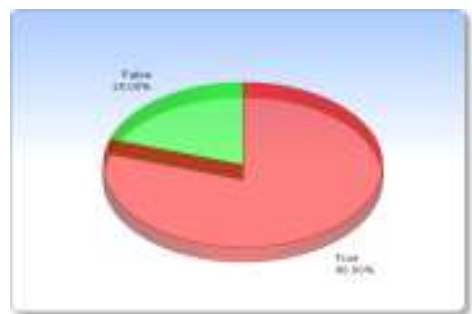

Figure:3.2

7. In classroom communications, male students receive more reprimands and criticism than female students.

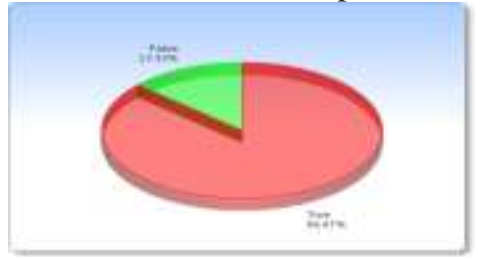

Figure:3.3

8. Women are more likely than men to disclose information on intimate personal concerns.

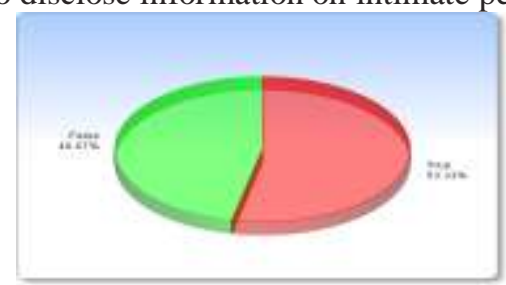

Figure:3.4

9. Female speakers are more animated in their conversational style than are male speakers.

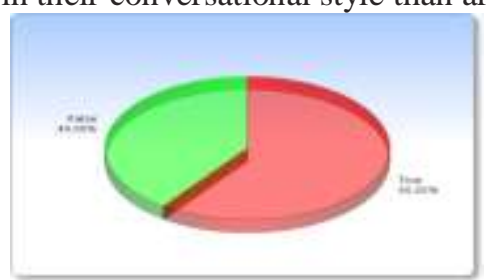

Figure:3.5 
10. Women use less personal space than men.

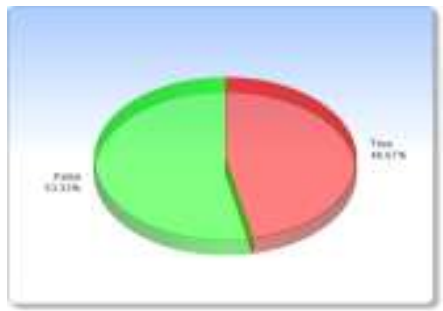

Figure:3.6

11. When a male speaks, he is listened to more carefully than a female speaker, even when she makes an identical presentation.

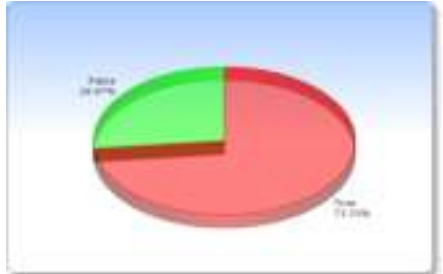

Figure:3.7

12. In general, women speak in a more tentative style than do men

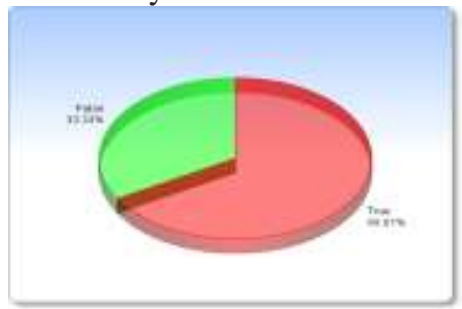

Figure:3.8

13. Women are more likely to answer questions that are not addressed to them

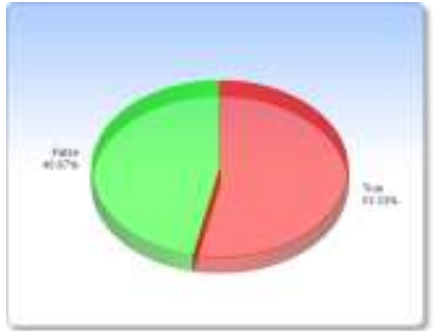

Figure:3.9

14. Female managers are seen by both male and female subordinates as better communicators than male managers.

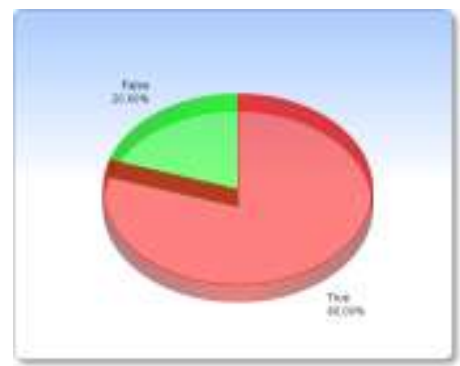

Figure:4.1 


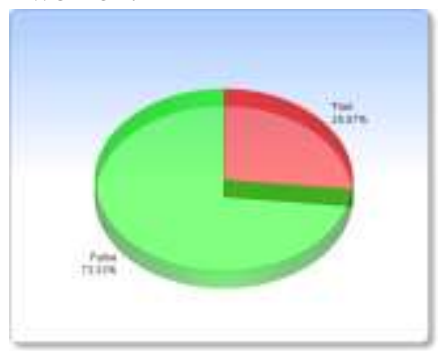

Figure:4.2

Being diplomatic is a trait that can't be specified on gender basis but still would say the females have an edge in this trait as well, most men at times act as open ended shells. And this is what drives us to next parameter of being helpful and asking for help. The males are victimized more often as being the helping agents to the females while the females balance the other proportion. Conversation with a female is seldom off course though when they are the source you end up tally marking the number of fillers of all sorts while you are made to hear the phrases "Why aren't you listening to me?" which also very well states who more often lectures during a conversation.

Though researchers have predicted the disappearance of gender communication differences as women moved into higher management positions, but the gap or "disconnection" still persists. It would behove men and women to listen to each other and be more open to learning from differences rather than allowing them to stifle growth and ability to communicate with one another. So males and females office personnel working in different level and positions in the organisation or in different branches of an organisation should be aware of the differences and use the proper conversational style to communicate as per the needs and demands of situation of the workplace. It doesn't mean that female office personnel should necessarily adopt male's report style and vice versa, it means according to the nature of working place they should collaborate with each other in communication so as to work effectively with the proper communication style so as to disallow the conflicts to rise amongst them.

Thus men and women communicate with each other in their own communication styles, they also follow their individual strategies and approaches but the purpose remain same that is to build bridges between Mars and Venus. Men's and women's differing communication styles are based both in science and nature. As the ancient hunters and gatherers, men were often put into a position of competition. They were competing against nature while trying to hunt and capture dinner. They were competing against one another for tribal status and mates. Winning, whether in a fight against an animal or a fellow tribesman, meant staying alive. Women, on the other hand, were often put into a position of cooperation as the family caretakers. They would band together to help with child care and other domestic duties. For women, avoiding fights meant staying alive. That history still affects us today. Men are competitive and hierarchical. They establish rank and status. Women look for similarities and value cooperation. In conclusion, no matter what communication style is adopted both men and women will communicate in different ways. Men will take the approach of instrumental communication style where they want the answer right away and establish their hierarchy and supremacy. Women, on the other hand, will be more of an expressive style of communication as they will be able to confide in others and are more sensitive to issues than men women will be able to build, maintain and strengthen the relationship.

\section{References}

[1] Women and Men by Sophie Hahn and Anne Litwin Published in Managing in the Age of Change: Essential Skills to Manage Today's Workforce, Roger A. Ritvo, Anne Litwin, and Lee Butler, editors, Burr Ridge, Illinois: IRWIN Professional Publishing, 1995 p.98.

[2] Martha Barletta to Nancy Clark in "Women's Media'.

[3] Deborah Tannen. (1991), How to Close the Communication Gap between Men and Women, article from McCall's May, v. 118, n8, p.100.

[4] Deborah Tannen. (1991), How to Close the Communication Gap between Men and Women, article from McCall's May, v. 118, n8, p.97.

[5] Deborah Tannen. (1991), How to Close the Communication Gap between Men and Women, article from McCall's May, v. 118, n8, p.100.

[6] Warren Farrell, Why Men Are the Way They Are, New York: The Barkley Publishing Group, 1988 p.235. 